\title{
A description of the final stadium larva of Calicnemia gulinensis Yu \& Bu, 2008 (Odonata: Platycnemididae)
}

\author{
Xueyi Chen and Xin $\mathrm{Yu}^{*}$ \\ College of Life Sciences, Chongqing Normal University, Chongqing, PR China
}

(Received 6 March 2020; final version received 22 April 2020)

\begin{abstract}
The final stadium larva of Calicnemia gulinensis is described here for the first time. The larva can be distinguished from other known species of the genus Calicnemia by the arrangement of setae on premental edges and the number of setae on labial palpi. The important morphological characters of the caudal gills and the possible functional adaptation are discussed briefly.
\end{abstract}

Keywords: Zygoptera; China; larval characters; functional adaptation; dragonfly

\section{Introduction}

The genus Calicnemia Strand, 1928 is a group of bright colored (usually red or orange), small platycnemidid damselflies, occurring in Southeast Asia, India, and China. So far, 24 species of this genus have been recorded worldwide (Schorr \& Paulson, 2019), among which 12 occur in China (Yu, 2010). In contrast to the well-described adults of Calicnemia, very few larvae have been described properly. The main reason for this, as Lieftink (1984) has mentioned, is due to the difficulty to associate larvae with adults. Laidlaw (1917) first noted the special larval character of Calicnemia, namely "short, spear-head liked gill lamellae with triradiate transverse section". Kumar and Prasad (1977) described a larva from Dehra Dun (India) identified as Calicnemia miles (Laidlaw, 1917). Kiauta and Kiauta (1982) described another larva of Calicnemia species from Nepal based on the karyotypic morphology and chromosome numbers which was subsequently confirmed by Lieftinck (1984) as C. miniata. In his excellent work, Lieftinck (1984) reviewed adults of all species of Calicnemia known at that time, and gave valuable remarks on larval taxonomy and biology. He provided detailed description and figures of the larva of $C$. miniata, and indicated that the larva described in Kumar and Prasad (1977) is actually C. eximia rather than C. miles. Dawn (2019) redescribed larvae of C. eximia and C. miniata with color photos of character and habitat. Therefore, so far, in the genus Calicnemia, only larvae of $C$. eximia and $C$. miniata were described. China has high species diversity and high level of endemism of Calicnemia (Yu \& Bu, 2008). In the present study, the larva of Chinese endemic species C. gulinensis was described for the first time. Furthermore, the possible function of its special caudal gills was discussed preliminarily.

*Corresponding author. Email: lannysummer@163.com 


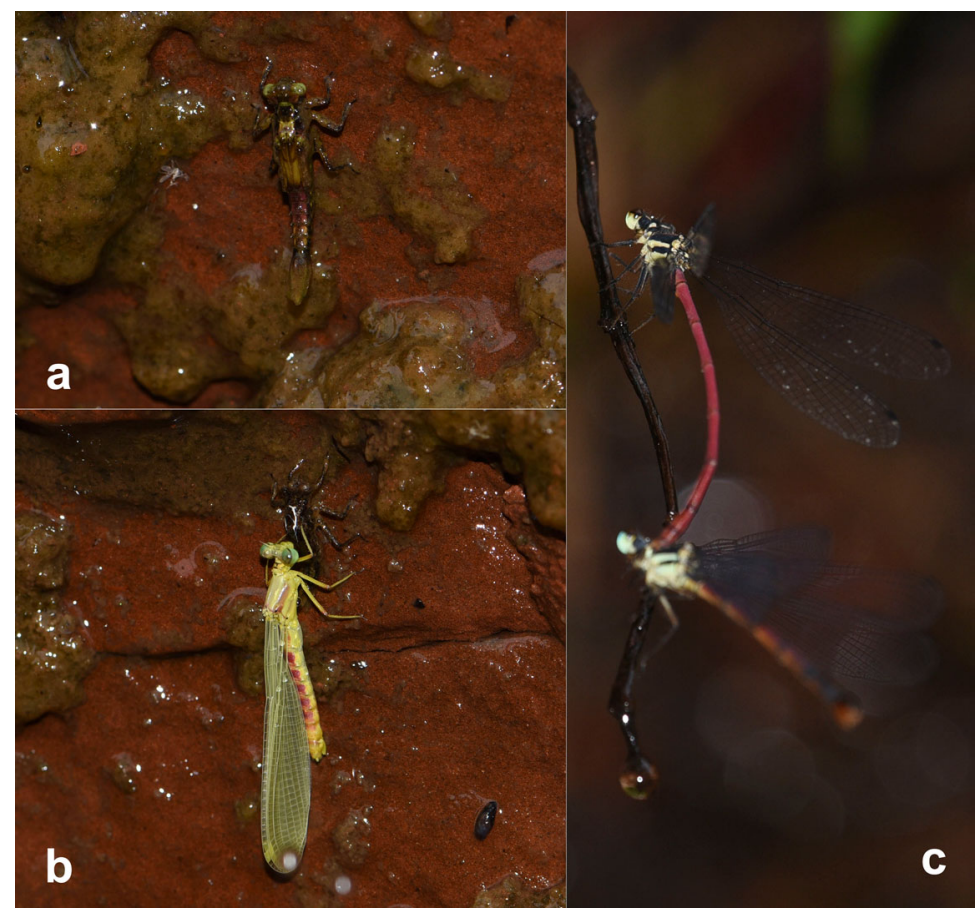

Figure 1. Field photos of F-0 larva (a), just emerged adult (b) and adults in tandem (c) of Calicnemia gulinensis taken by Xin Yu.

\section{Area and methods}

During a field work in Simianshan, Chongqing, China $\left(28.6^{\circ} \mathrm{N}, 106.4^{\circ} \mathrm{E}, 1063 \mathrm{~m}\right)$ in May 2019 , one F-0 larva (Figure 1a) and one recently emerged adult with exuviae (Figure 1b) were collected on a seeping, vertical rock face (Figure 2). Several teneral adults were also observed nearby. The newly emerged adult and those teneral ones were identified as $C$. gulinensis. About one month later, in the same place, numbers of mature adults of this species were found in copulation. All the photos of living individuals were taken in the field with a digital camera (Nikon D7500, Bangkok, Thailand). Specimen photos were taken in the laboratory using LY-WN-HPCCD20 (Chengdu, China) high definition digital imaging system. Specimens were preserved in $95 \%$ ethanol and were examined and dissected under a CNOPTEC SZ810 (Chongqing, China) stereomicroscope.

\section{Taxonomic account}

Material examined

Larva of Calicnemia gulinensis Yu \& Bu, 2008

1o exuviae and 1o F-0 larva, Simianshan, Chongqing, China, 30 May 2019, Xin Yu leg.

\section{Description}

A relatively robust zygopteran with a large head. The overall body color yellowish, lacking distinct bands or marks, lateral sides of abdomen dark brown. Caudal gills short, spear-head shaped (Figures 3, 6). 


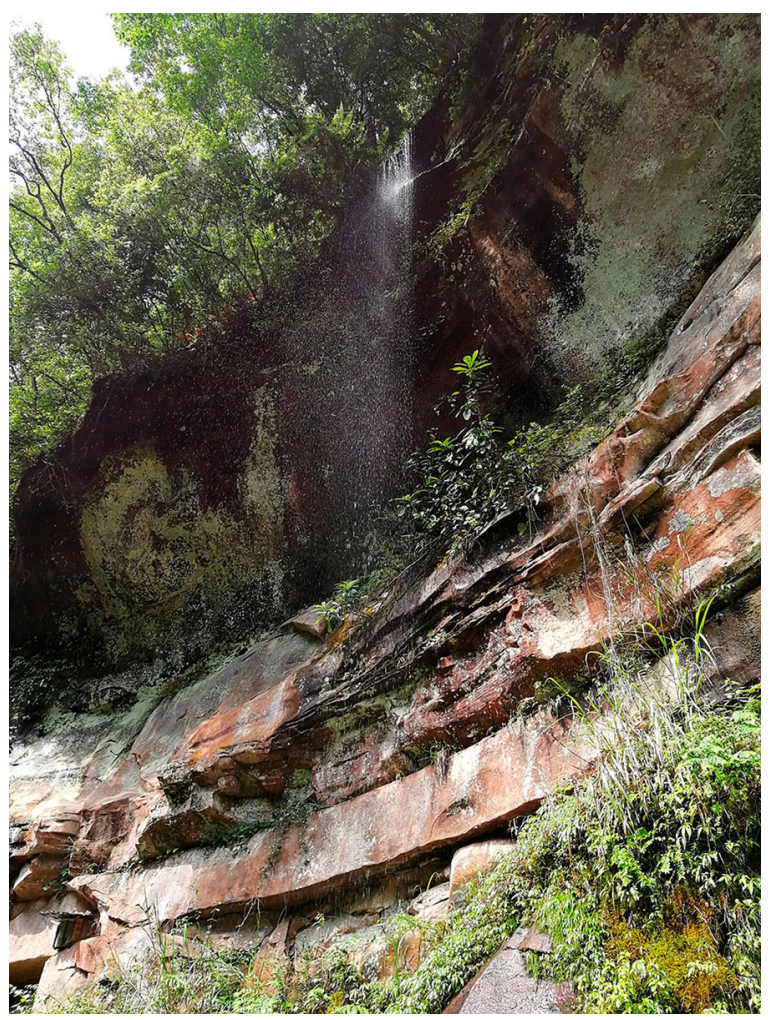

Figure 2. Habitat of Calicnemia gulinensis larva taken by Xin Yu.

a

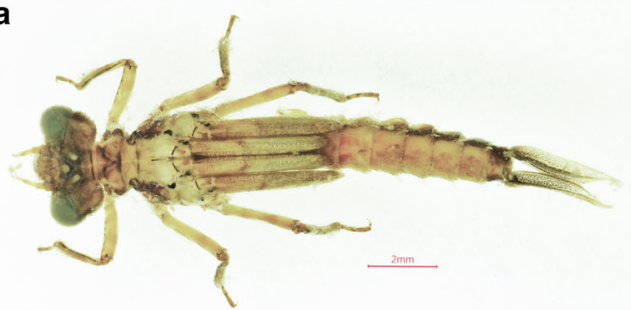

b

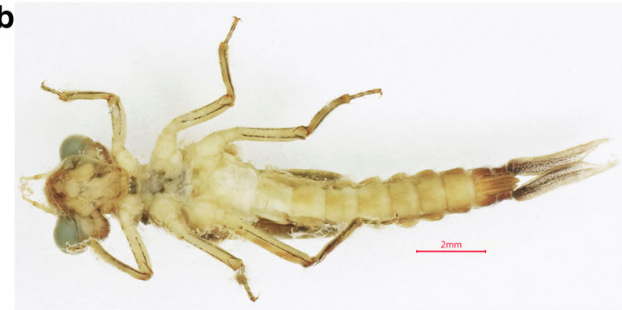

Figure 3. Habitus of Calicnemia gulinensis with the middle caudal gill removed, (a) dorsal view; (b) ventral view.

Head. Relatively broad, trapezoidal, about twice as broad as long, with bulging eyes. Antennae 7-segmented, short and robust, segments from base to apical become tapered gradually with segment 3 longer than each other segments (Figure 3a, b). Prementum pentagonal, not elongate, strongly produced distally (Figure 4a), with many strong short setae on both sides but not along premental margins at base (Figure 4b), and a pair of small setae in the center (Figure 4c). Ligula convex with uniform marginal denticles. Labial palpi robust with two strong and three weak setae on each side (Figure 4d); movable hook long, robust and incurved. Maxilla (Figure 5a, b) slightly longer than broad, covered with long hairs; galea and lacinia partly fused; lacinia terminating in four long sharp spines forming a curved, inward-directed, pitchfork-like structure; galea with two short robust spines; palp with short basal segment and a single long bananashaped terminal segment, reaching almost to distal spines on galeo-lacinia, covered in dense long setae. Left mandible (Figure 5c) with similar incisors; molar crest relatively developed (L1234 

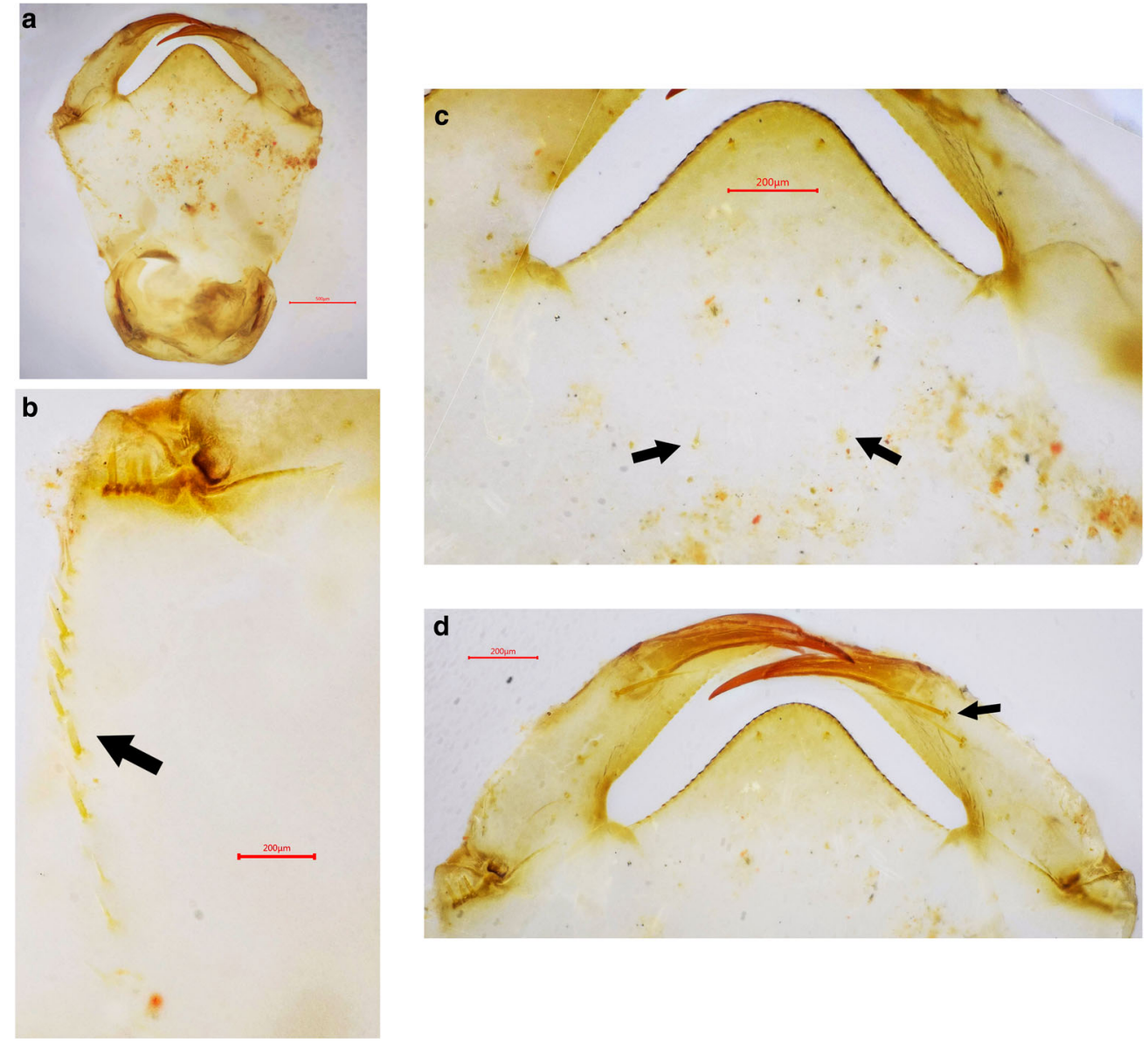

Figure 4. Prementum of Calicnemia gulinensis, (a) dorsal view; (b) same, showing the strong short setae on the edge; (c) same, showing the central setae; (d) same, showing the labial palps with setae.

y ab $2<1<4<3$, b $>$ a). Right mandible (Figure 5d) with four rather long and well developed incisors and a fifth innermost tooth; molar crest is greatly reduced (thus, in the terminology of Watson [1956], R1234 y a, $2<1<3<4$ ).

Thorax. Prothorax not strong, narrower than both head and synthorax; meso- and metathorax almost rectangular in shape. Legs moderately long, covered with pale hairs, with dark spines on the side. Wing pads not divergent, narrow, moderately long, just reaching the end of S4.

Abdomen. Slender, elongate moderately, covered with small hairs, lateral edges of all segments extended outward a little. Gonapophyses well developed, beyond S10. Middle caudal gill rectangular pyramid shaped (Figure 6a-c), a little longer than the triangular pyramid shaped (Figure 6d-f) laterals, all covered with sparse long pale hairs.

Measurements (mm, $\mathrm{n}=2$ ). Body length (including caudal gills) 17.6-17.9.

\section{Diagnosis}

Generally, larvae of the genus Calicnemia are similar. Identification characters are concentrated on the labium. The labium of $C$. gulinensis (Figure 4a) is similar to that of $C$. eximia ( $c f$. Dawn, 2019, Figure 1c), both longer than C. miniata (cf. Dawn, 2019, figure 1d). C. gulinen- 

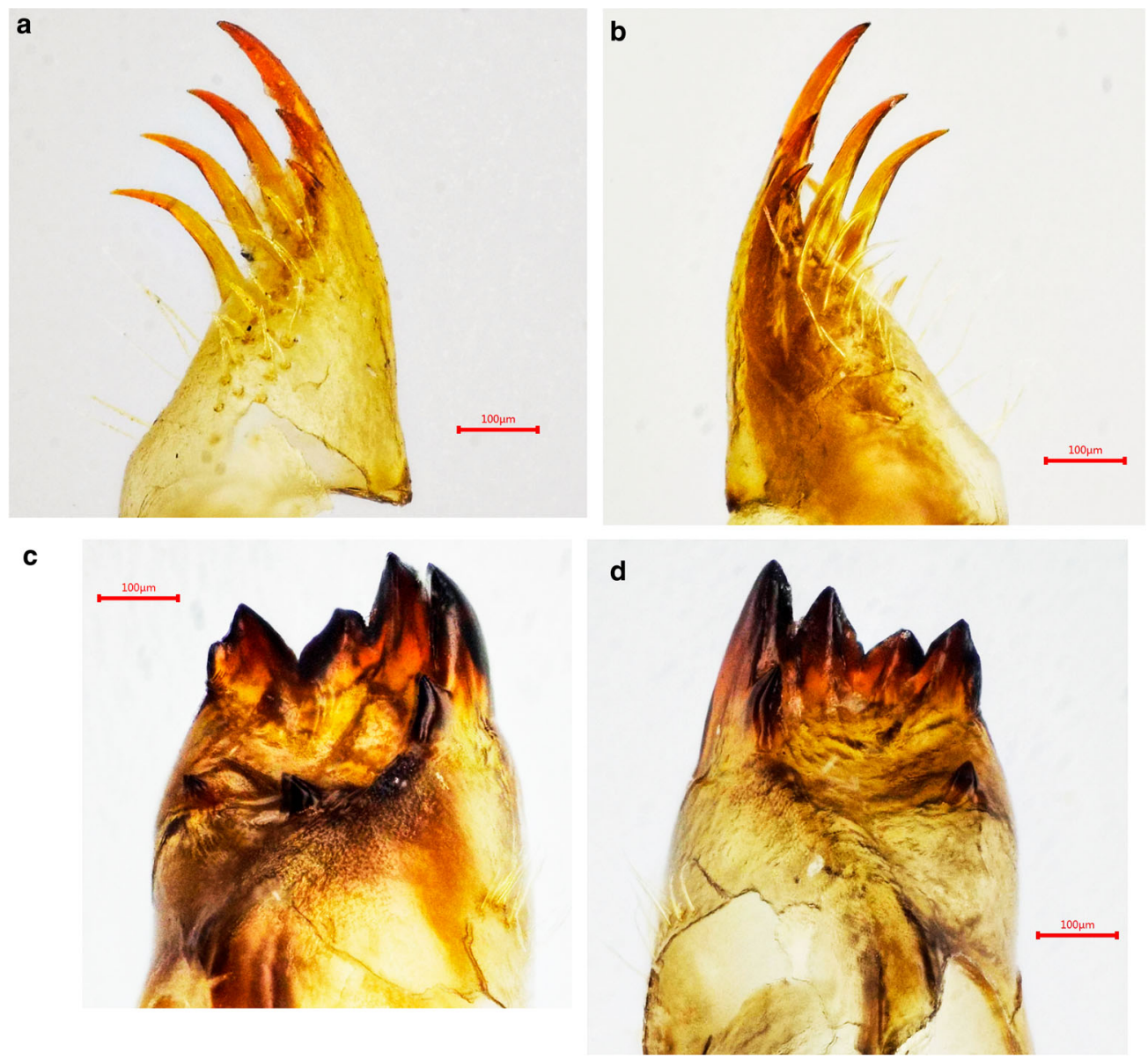

Figure 5. Posterior surface of maxilla and mandible of Calicnemia gulinensis, (a) left maxilla; (b) right maxilla; (c) left mandible; (d) right mandible.

sis (Figure 4c) and C. miniata (cf. Dawn, 2019, figure 1d) present a pair of premental setae, which is absent in C. eximia (cf. Dawn, 2019, figure 1c). C. gulinensis has no more than two strong setae on each labial palpus (Figure 4d), whereas $C$. eximia and $C$. miniata each have three (cf. Dawn, 2019, figure 1c, d). Furthermore, in C. gulinensis, the strong short setae on edges of the prementum bend inwards at base, with a total number more than 8 (Figure $4 \mathrm{~b}$ ). Whereas in C. eximia (cf. Dawn, 2019, figure 1c) and C. miniata (cf. Dawn, 2019, figure 1d), the setae were always parallel with the edge and the number less than 5 .

\section{Microhabitat and behavior}

Larvae were found on a seeping, vertical rock face, just under a small waterfall (Figure 2). One month later, adults in copulation of the same species were found here also (Figure 1c). Larvae have protective coloration and moss or fungi covered their body, They are torpid most of the time in the field. Therefore, larvae are very difficult to distinguish from the background. 

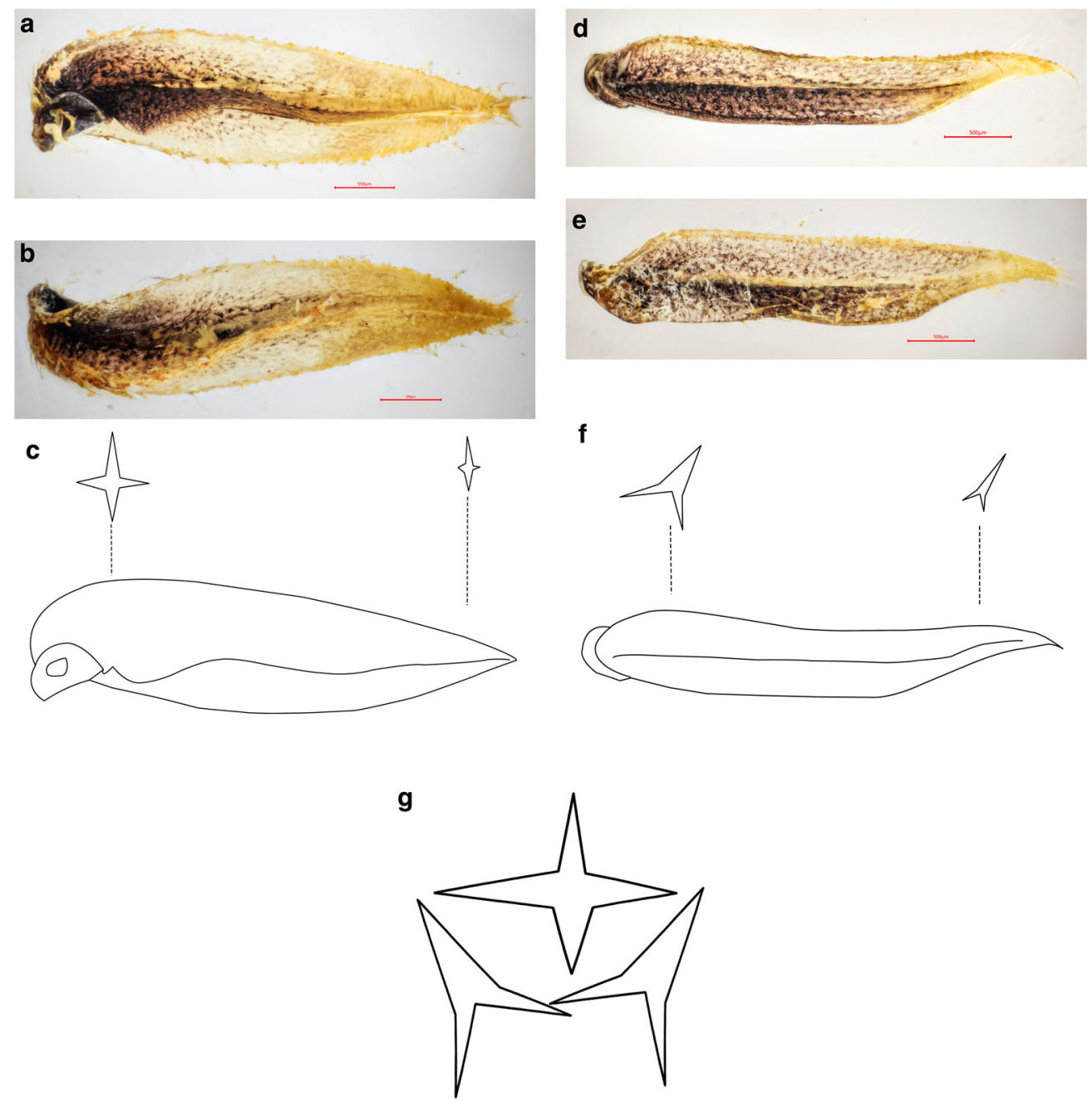

Figure 6. Caudal gills of Calicnemia gulinensis, (a) middle, ventral view; (b) middle, dorsal view; (c) cross section of middle; (d) right lateral, inner surface; (e) left lateral, posterior surface; (f) cross section of right lateral; (g) cross section of all caudal gills.

\section{Discussion}

The most striking feature of larvae of Calicnemia is the shape of their caudal gills. They are short, spear-head liked with triradiate transverse section (Laidlaw, 1917), more or less saccoid gills (Lieftink, 1984). This feature is very different from their congeners in family Platycnemididae, like those of Copera, Platycnemis, and also the most closed related genus Coeliccia (Dijkstra, Kalkman, Dow, Stokvis, \& Van Tol, 2014). We agree with Lieftinck (1984) that "this special morphological feature strongly suggests a functional adaptation to a particular environment". Although some members may also develop in ponded streams and marshes with clear cold water (Lieftink, 1984) or in rapid streams (Kiauta \& Kiauta, 1982), most known Calicnemia species live in a similar semiaquatic environment which is special, if not unique, in Platycnemididae. The habitats include permanently wet rocks covered by organic litter, mud and moss (Kiauta \& Kiauta, 1982); a kind of helocrene-water seeping out of the ground among vegetation and plenty of dead leaves; or absolutely vertical rock between some rootlets and with the water 
trickling down very slowly (Lieftinck, 1984), usually near a waterfall (Kiauta \& Kiauta, 1982 and the present study). Living in such an environment, the caudal gills of Calicnemia larvae are expected to be modified into a strong ridged style forming a pyramid shape (Figure 6). We found the transverse section of the lateral gill in C. gulinensis is triradiate (Figure $6 \mathrm{~d}-\mathrm{f}$ ), but is tetraradiate in the middle one (Figure 6a-c). According to the living photo (Figure 1a), the caudal gills of $C$. gulinensis, when put together, form a special shape with the transverse section like in Figure $6 \mathrm{~g}$. We suppose this kind of caudal gills can let water flush down along the body without any resistance. And, when necessary, the gill can open out easier than the lamellae shaped gills of their congeners. This kind of caudal gill is very strong, which may help larvae cling to the cliff or rock surface more firmly (Figure 1a). Although both Laidlaw (1917) and Dawn (2019) have mentioned that "the transverse section of caudal gill is triradiate", they did not emphasize whether both middle and lateral gills were the same. According to figure $1 \mathrm{~h}$ in Dawn (2019), the middle gill of $C$. eximia could be tetraradiate in transverse section.

In summary, species of Calicnemia are intriguing damselflies living in special habitats, and studying their larvae ecology and behavior is of great significance.

\section{Acknowledgements}

We are grateful to reviewers and editor for their valuable remarks and suggestions.

\section{Funding}

This project was supported by the Chongqing Basic Research and Frontier Exploration Special Project (No. cstc2018jcyjAX0415) and the grant of Ministry of Science and Technology of China (No. 2015FY210300).

\section{References}

Dawn, P. (2019). Description of the last instar larva of Calicnemia eximia (Selys, 1863) (Odonata: Platycnemididae) from West Bengal, India. Zootaxa, 4657(1), 183-187.

Dijkstra, K. D. B., Kalkman, V. J., Dow, R. A., Stokvis, F. R., \& Van Tol, J. (2014). Redefining the damselfly families: a comprehensive molecular phylogeny of Zygoptera (Odonata). Systematic Entomology, 39(1), 68-96. doi:10.1111/syen.1203

Kiauta, B., \& Kiauta, M. (1982). The chromosome numbers of sixteen dragonfly species from the Arun Valley, eastern Nepal. Notulae Odonatologicae, 1(9): 143-145.

Kumar, A., \& Prasad, M. (1977). Last instar larvae of two Odonata species from Western Himalayas. Entomon, 2(2), $225-230$.

Laidlaw, F. F. (1917). A list of the dragonflies recorded from Indian Empire, pt 2. The family Agrionidae. Records of the Indian Museum, 13, 321-348, figs 13-15.

Lieftinck, M. A. (1984). Further notes on the specific characters of Calicnemia Strand, with a key to the males and remarks on some larval forms (Zygoptera: Platycnemididae). Odonatologica, 13(3), 351-375. http://natuurtijdschriften.nl/record/591665

Schorr, M., \& Paulson, D. (2019). World list of Odonata. University of Puget Sound [Electronic Database]. Retrieved December 14, 2019 from http://www.pugetsound.edu/academics/academic-resources/slater-museum/biodiversityresources/dragonflies/world-odonata-list2

Yu, X. (2010). Odonata Research [Internet]. Retrieved December 13, 2019 from http://www.china-odonata.top

Yu, X., \& Bu, W. J. (2008). A study of the genus Calicnemia Strand in China, with the descriptions of two new species (Zygoptera: Platycnemididae). Odonatologica, 37(3), 247-255. http://natuurtijdschriften.nl/record/592633 